\title{
DRIVING RESPONSIBLE RESEARCH AND INNOVATION: SCIENCE, SOCIETY AND THE ENERGY MOVEMENT
}

\author{
N. Malan* \\ Faculty of Humanities \\ e-mail:nmalan@uj.ac.za
}

\section{Z. Simpson*}

Faculty of Engineering and the Built Environment

e-mail: zsimpson@uj.ac.za

\section{N. Janse van Rensburg*}

Faculty of Engineering and the Built Environment

e-mail: nickeyjvr@uj.ac.za

*University of Johannesburg

Johannesburg, South Africa

\section{ABSTRACT}

South Africa faces the challenges of poverty, unemployment and inequality, as well as looming problems regarding water, energy and food. Science, technology and engineering are able to address some of these challenges but are often inaccessible and unfamiliar to the general public. Research and innovation in these fields needs to be increased, and undertaken in partnership with multidisciplinary stakeholders. This article uses the example of an engineering education initiative, the African Solar Drive, to illustrate how this may be achieved. It discusses recent developments in the philosophy of science that have emphasised responsibility in research and development, the similarities of these with action research methodologies and the relevance of these for the concerns South Africa faces at the moment. It presents a general methodology for science-society engagement and locates the African Solar Drive as a prelude to such engagement between higher education and the general public.

Key words: Science-society engagement; renewable energy; sustainable development; higher education; science education

\section{INTRODUCTION}

South Africa faces varied and complex social and economic problems that severely affect poor and working class communities (Balwanz and Hlatshwayo 2015). This includes the general challenges of poverty, unemployment and inequality, which are exacerbated by the looming global problems of energy shortage (World Economic Forum 2014), food insecurity and 
agricultural failure (McIntyre et al. 2009), and water scarcity (World Water Assessment Programme 2012). These are not natural phenomena, but are brought about by the inequitable operation of economic markets. They are also made worse by the fact that systems of education and training have too often failed to respond to these challenges. In South Africa, 'a quality public education system remains a chimera' and expenditure thereon, which is already significant, needs to increase by between 20 and 30 per cent to address the backlog (Vally 2015, 154, 158).

To reorient science and technology towards conducting 'responsible research and innovation' (Owen, Bessant and Heintz 2013) requires the deployment of methods such as action research (Brydon-Miller, Greenwood and Maguire 2003) and social innovation (Manzini 2015; Moulaert et al. 2013). Science and technology education needs to incorporate activities that are not normally considered part of science and technology research and development so as to engage in technology design that speaks directly to social concerns. In so doing, education can allow its beneficiaries to live 'lives of value and dignity, in harmony with our earth and one another' (Harley 2015, 77). This article discusses a methodology for responsible engagement between science (education) and society and argues that it is through such engagement that solutions to the many problems facing us may be found.

As a case in point, we discuss the African Solar Drive, the goal of which was two-fold: the larger goal was to identify solutions to pressing social problems related to energy, while a more immediate goal was to promote science, technology, engineering and mathematics (STEM) education amongst marginalized communities. Although we would be the first to acknowledge the limited reach of the Solar Drive, we introduce it here as a first step towards building a constituency through which science education can be promoted as a socially responsible activity.

This article reviews key theoretical and methodological aspects involved in facilitating engagement between science and society. These aspects include participatory action research, social innovation and the question of 'responsible' scientific research, amongst other topics. Thereafter, the article discusses a methodology to accomplish such engagement (a bricolage derived from Holtmann 2015; Manzini 2015; Anderson and McLachlan 2015), before applying this model to the African Solar Drive. The article concludes with suggestions as to how this kind of engagement can be expanded so as to foster meaningful interaction between science and society.

\section{SCIENCE AND SOCIETY: EXPLORING APPROACHES TO ENGAGEMENT}


Current approaches to science-society engagement incorporate calls for 'responsible research and innovation’ (Stilgoe, Owen and Macnaghten 2013; Owen, Bessant and Heintz 2013), which includes promoting 'public understanding of Science’ (Miller 2001; Bauer 2009). Too often this refers simply to the governance of scientists, their work and their outcomes, that is, what Lotriet (2015) calls 'soft' forms of science-society engagement. However, participatory research methods require communities to lead change for themselves, though this is undermined by the fact that communities are often unable to release themselves from the daily demands of survival (Balwanz and Hlatshwayo 2015). As such, there is 'greater responsibility on institutions of education to promote research as praxis and education as change' (Balwanz and Hlatshwayo 2015, 148). It is for this reason that recent work within the philosophy of science has installed a progressive, participatory and engaged democratic paradigm for science-society relations as both possible and desirable (Lotriet 2015).

This work falls within a number of complementary approaches. These include the traditions of action and participatory research (Brydon-Miller, Greenwood and Maguire 2003) and design for social innovation (Manzini 2015; Smithsonian Institution 2013). Such approaches seek to identify those moments, procedures and interactions that can push science, and science educators, to act in a socially responsible manner and address the pressing needs of our society. The sections that follow discuss these approaches in greater detail.

\section{Action research, participation and development}

Action research 'seeks to bring together action and reflection, theory and practice, in participation with others, in the pursuit of practical solutions to issues of pressing concern to people, and more generally the flourishing of individual persons and their communities' (Reason and Bradbury, in Brydon-Miller, Greenwood and Maguire 2003, 10). Action research derives from the work of Kurt Lewin, who advocated for 'democratic participation rather than autocratic coercion' in order to 'develop social relationships of groups and between groups to sustain communication and cooperation' (Adelman 1993, 7). Lewin's work demonstrates 'social science as a means to help solve social problems' (Adelman 1993, 8). Action research also has radicalised roots stemming from Paolo Freire (2005 [1970]) and the 'People's Science Movement' (Rahman n.d.) that emerged in 1978, and that is clearly appropriate to the concerns of South Africa.

Action research has become a system of deliberative and communicative procedures through which a group can investigate a particular situation, develop plans to address specific or general issues, implement these and reflect on their efficacy. As it has proliferated, numerous 
variations of action research have come into use. However, all of these variations begin with questions such as 'what is?' (Burns 2012, 93), 'if so?' (Adelman 1993, 8) and 'how do we want it to be?' (Holtmann 2015). This leads to the formation of groups who collaboratively conduct inquiry into social problems. A process is constructed where people, scientists and the general public as well as specific stakeholders, identify problems and participate in sessions where alternatives for action are explored and implemented. This leads to another cycle of action and reflection. Stories from 'ordinary' people thus become directives or nudges for new directions in scientific research.

Current examples of participatory action research are skewed towards systems thinking (Burns 2014; Anderson and McLachlan 2015) and cross-system dialogue, experimentation and action (Malan 2015). In such endeavours, use is made of traditional and social media, internet blogs, and advocacy campaigns to enable diverse actors to deliberate and collaborate on the development of new systems. Anderson and McLachlan $(2015,4)$ aver that this approach counters the tendency for high-impact research to re-affirm power inequalities and which 'risks reproducing and even deepening the inequalities that pervade wider society'. This echoes Owen, Bessant and Heintz (2013, xii) who argue that science creates 'organized irresponsibility' not only by its choice of problems to be studied, but in the way it excludes social values from inquiry.

Science itself thus contributes to social problems and that means science and, in particular, science education needs to change. For our purposes, this indicates a need to situate and contextualise science's engagement with society within broader currents of change, and strategically focus on specific issues, such as alternative energies. Science should be seen as one of many actors within a social network of engagement (Lotriet 2015). The solution of social problems requires concerted and coordinated effort, and scientific input into these processes needs to be made in such a way that others are able to use it. Furthermore, scientific knowledge is susceptible to use by undesirable actors and interests, and it is thus also necessary for scientists to develop the ability to anticipate such abuse.

Linked to participatory action research is participatory development, which constitutes a critique of science, linking it to underdevelopment (Chambers 1992). Chambers has written on participatory learning and action in the field of International Development, where the predominant mode of science is the evaluation study. Continued underdevelopment, Chambers argues, suggests that such a rationalist, clinical approach to evaluating the impact of development on people is inappropriate. Chambers (1992, 516-517) goes on to identify four 'defects' in social scientific inquiry into development: the first is that 'things have come before 
people'; second, 'poorer people have been easily neglected'; third, 'conventional methods of social investigation have been ... irrelevant, late, wrong or unusable'; and, finally, 'information has been acquired, owned, and analysed mainly or only by outsiders'. This emphasises that scientific knowledge, technologies and practices must take cognisance of social context so as to link science with social values and that one of the benefits of science-society engagement may be to slow science down (Lotriet 2015) and address inequalities in access to the products of science.

'Development', as a grand project of society (McMichael 2012), is both susceptible to science and influences science by altering the material bases wherein scientific research is conducted. To say that science should address social problems means that science should partake in the grand project of 'development', but in such a way that the needs of the poor and marginalised come first. At present, scientists and science educators have not been entirely successful in promoting themselves as relevant to the concerns of the general public. Scientists need to play a role within development teams and the knowledge they produce must be useful for such teams. This can be achieved through multi-stakeholder engagement.

\section{Systemic action research and multi-stakeholder engagement}

Action research, particularly those variants that aim for comprehensive social change, has evolved into two noteworthy branches. One concerns systemic action research and the other concerns multi-stakeholder engagement. Both lead, albeit in different ways, to a distinct approach to social change, one that incorporates 'social innovation', the 'social economy' (Fowler 2000; Murray, Caulier-Grace and Mulgan 2010; Moulaert et al. 2013; Manzini 2015) and 'social enterprise' (Borzaga and Defourney 2001) so as to reconcile growth with equity.

If action research is concerned with the empowerment of marginalised communities through development and social change processes, systemic action research focusses instead on the complex networks through which resources, power, people and goods flow:

Systemic practitioners/facilitators see power relationships as highly dynamic flows through complex webs of inter-relationships. To even begin to understand them, it is necessary to see them through multiple perspectives. This means engaging and working with people that have completely different interests within the system. (Burns 2012, 99).

Systemic action research adapts action research methods to take note of 'systemic interrelationships' (Burns 2014, 5) amongst social actors (scientists constituting but one category of actors). It also adopts 'contemporary systems and complexity theory [which sees] change as highly relational and dependent on the deeper dynamics of a whole system’ (Burns 2014, 5). This has implications for scientists engaged with society in an attempt to solve social problems: 
scientists need to engage in self-reflection regarding how their own conduct, the organisations they belong to, and the power relations present influence their work, the reception of their findings and perhaps even the findings themselves. Hence, 'sustainable change requires us to change the system within which the changes are taking place' (Burns 2014, 7).

Multi-stakeholder engagement approaches, meanwhile, share many of the perspectives adopted by systemic action research and postulate the creation of action teams from business, policy, science and societal organisations that promote and steer change (Regeer, Mager and Van Oorsouw 2011, 24). The teams also include one 'process' or 'reflection monitor' that can operationalise and implement reflective exercises and shape, reverse or push forward engagement processes in multi-stakeholder events. This creates socially robust solutions (Regeer, Mager and Van Oorsouw 2011, 25) and incorporates, ethically and normatively, benefit for people, planet and profit. Such an approach attempts to 'co-create shared value' through fostering 'emergent solutions' (Regeer, Mager and Van Oorsouw 2011, 25). By 'generating action (and learning from action) which shifts the status quo system, dynamic new possibilities emerge, and systems start to realign, opening up the possibilities for convergence' (Burns 2014, 11).

The notion of the stakeholder brings about movement towards democratisation of knowledge, and towards participatory strategies for the development and implementation of the outcomes of scientific processes. Bunders and Regeer $(2009,47-48)$ point out that 'introducing the viewpoints of stakeholders can provide new, valuable perspectives on the problem, but also new information that is relevant in finding solutions'. The key issue here is the 'unstructured' (Bunders and Regeer 2009, 48) nature of social problems. Traditional inquiry is based on 'Newtonian mechanistic physics' that are 'not readily adaptable to contemporary conceptions of interacting open systems and to contemporary concerns with equity' (Rittel and Webber 1973, 156).

To address these 'unstructured' social problems, not only do we need to mobilise and organise the scientist as part of an interdisciplinary team including other scientists, policymakers and representatives who speak for the full gamut of society; we also need engagement methods that can facilitate and structure these interactions. These engagement processes do not take the place of scientific experimentation and method. Instead, they rely on pertinent scientific inputs in order to address social problems, and allow the rigorous application of scientific research in such contexts that are then shaped by numerous stakeholders. These engagement processes also supply information that is crucial in the design of technology and its implementation in particular social contexts. Anderson and McLachlan $(2015,6)$ present these 
dialogic encounters as a set of upward-moving spirals with key events or meetings in which groups 'observe', 'reflect', 'plan' and 'act', each of which is made up of sub-cycles in which the same processes are undertaken. The process of linking science education to society is, therefore, process-oriented, flexible, open to improvisation, participative and engaged. It culminates in the notion of 'social innovation'.

\section{Social innovation and the social economy}

Social innovation (Hart et al. 2015; Murray, Caulier-Grace and Mulgan 2010) resembles social entrepreneurship (Fowler 2000; Murray, Caulier-Grace and Mulgan 2010) and the notion of the 'social economy' (Borzaga and Defourney 2001). Key to these notions is the idea, derived from the philosopher Michael Polanyi (2001 [1944], 48), that 'man’s [sic] economy ... is submerged in his social relationships'. As such, a determining factor is how social action relates to the relationships and networks that are meaningful in the life of a person. Moulaert and Nussbaumer (2005, 2084) point out that 'social innovation becomes a proactive strategy for the innovation or revival of social capital, in interaction with other types of capital'. Linking science education to society builds social capital and with that the ability of a community to respond to the pressing issues it faces. By linking science education and society, science becomes part of society and its outcomes and processes become the means by which social actors expand their networks. Science becomes a project that ordinary people participate in.

It is instructive to see how social innovation has been defined. Hart et al. $(2015,3)$ identify social innovation as two-pronged: it is a 'social product' that stresses the welfare and social benefits of products, but it is also an organisational or social arrangement that enhances social collaboration. Hart et al. $(2015,3)$ combine these two definitions by arguing that 'social innovations are those new products, services, models and practices that concurrently meet social requirements and involve new social collaboration' and that 'such innovations must achieve broad systemic transformations’.

Despite this definition, it remains unclear how social innovation practices can be used to link science and society. To do this, it is useful to turn to work in the design professions that has developed methodologies for facilitating engagement between designers and society. The design professions, in accordance with the definition of social innovation above, have moved away from the design of mere products and have developed ways to allow 'everyone' to design their own worlds (Manzini 2015). Through combining these methodologies with participatory action research methods, we can arrive at a working model for science-society engagement. However, before this model can be fully understood, it is necessary to review Manzini’s general 
approach to social innovation.

Social innovation and change can be encouraged through events, through the development of new media (particularly electronic and social), through the use of spaces (where people can mingle and meet), through the creation of specific organisations or associational forms and patterns, and through the creation of new enterprises, technologies, services or systems. Manzini (2015) presents a general approach to creating these, and his contribution allows for the expansion of scientists' toolkits to include the inputs of the general public. His views echo much of what has taken place regarding participatory action research and multi-stakeholder engagement. However, he presents this information in a way that is accessible to scientists and designers, both groups that have not traditionally engaged with the public. As such, engagement between science and society should be based on specific methodologies (that approximate the action research cycle) that lead to, as Manzini (2015, 68-74) argues, the creation of specific projects, coalitions and networks that would allow innovative solutions to come forward. Manzini $(2015,77,93)$ proposes that innovation, which cannot be planned for, emerges from 'collaborative organisations' and 'collaborative encounters'. These organisations and encounters need to be connected to a diversity of social actors and action has to be operationalised at the local level. In the model below, overarching processes are stressed, but these should be used in conjunction with 'ethnographic interventions' (Fisher 2007, 155) in the minutiae of scientific research.

\section{A GENERAL MODEL OF SCIENCE-SOCIETY ENGAGEMENT}

Science-society engagement can be shallow or deep. Shallow engagement includes dissemination of findings, event-based engagement (such as in the case of the African Solar Drive) and public education, whilst deep engagement includes co-identification of scientific problems and co-participation in data gathering, discussion of findings and the translation of these into policy. Science-society engagement can take place through the creation of events, organisations or networks, enterprises, deliberative processes, and materials and media specifically purposed for this (Manzini 2015). During a singular event, such as the African Solar Drive, little space is made for deep engagement and deliberation amongst and between scientists (and students) and the general public. But, through the creation of deliberative processes, materials, media, organisations, networks and enterprises, deeper engagement becomes possible. Furthermore, in an individual event, very little control can be exercised over deliberation but, where such an event forms part of a bigger system, or 'learning architecture' (Burns 2014, 13), a trajectory of deliberation and inquiry can be fostered. This is elaborated 
upon in the concluding section of this article, where it is shown how shallow forms of engagement, such as the African Solar Drive, can be leveraged for the purpose of facilitating deep engagement between science and society.

Within an ideal engagement, teams made up of researchers and other stakeholders would embark on a structured programme of investigation, action, deliberation and engagement and, through these activities, develop insights, norms and relationships, both within the team and across society. Such engagement incorporates researchers who are able to develop new systems, artefacts or enterprises, bearing the considerations of the general public and, in an abstract sense, society in mind. Participation in teams and/or events is aimed at enabling the general public to become co-researchers that play a role in a more inclusive division of scientific labour. Inclusion of input from the general public is important as they are in a position to identify problems, contextualise those problems and pre-empt potential negative impacts of the research process. The key to understanding these engagements lies in a strategic division of scientific labour, where those able to identify problems collaborate in doing so with those who aim to develop solutions to those problems.

The model for science-society engagement proposed herein involves a sequence of events where collaborative and deliberative opportunities arise for developing plans for action. The model is a bricolage of the approaches discussed above, and includes the following stages.

First, there has to be opportunity to understand the context of the planned intervention, often called a ‘discovery’ phase. This provides an opportunity to recruit stakeholders (scientists and non-scientists alike) and enables informed understanding of the context, often by using a mix of social science methods and ordinary conversation. It is characteristic of social knowledge that seemingly insignificant facts can make a big difference later on in development projects. Only a deep appreciation of the local context, and specific techniques of engagement such as resource mapping, can reveal such information. This is particularly important, as people act on the basis of assumed 'social facts' and the literature is littered with examples of design oversights caused by limited understanding of the user context.

The second stage is often called the visioning stage where participants (and here sciencesociety engagement formally commences), in an open and facilitated session, are asked to imagine 'what it looks like when it is fixed' (Holtmann 2015). This enables a community to focus on solutions and establishes a 'baseline' or ideal end state that, in fact, constitutes the overall objectives of the intervention. It is not the solution to the problem, but the state that will be arrived at if the problem is significantly addressed.

The third stage is one of strategy development. Herein, broad plans of action are 
developed and intermediate mileposts established. These have to be broad as something like ‘sustainable energy use' will always have multiple dimensions, each of which can address the problem only in a concerted way. This leads to plans for multiple and parallel avenues of action.

These mileposts would identify targets or objectives that lead to the fourth stage: the creation and implementation of tactics, or concrete action plans. Here media are used to enable participants to develop imaginative solutions and plans. This is a creative stage where both scientists and society members actively participate. Tactical activities would include smaller action plans to realise intermediate objectives. These can often be accomplished by local actors, rather than project stakeholders, though stakeholders may play an oversight role and make adjustments as the process unfolds.

The final stages revolve around implementation as well as monitoring, and arrive at a point where the evaluation of the current project leads to the creation of a subsequent project that can be planned through a further visioning exercise. Implementation involves stakeholders actively exercising oversight over the activities implemented at the local level. Feedback loops are built into this stage so that the process can go back to any preceding stage. Formal and informal methods of data collection can be used and a strong monitoring and evaluation process can be incorporated herein.

In all these stages, there is an emphasis on diverse participation, cross-society action, and the blending of activism, inquiry and education. Large workshops can be managed by the use of World Café and Open Space that allow large groups to deliberate on a specific problem. Regeer, Mager and van Oorsouw (2011, 212-259) further identify Dynamic Learning Agenda as a tool to 'link long-term aims to concrete action', and focus group interviews, actor analysis, causal analysis, and timeline workshops as tools that can be used in the general model described above. These are all 'soft' tools in the sense that they merely inform and educate participants about the progress of the project. Hard actions, like rolling out solar technologies, would emerge from these soft processes.

The discussion above allows us to critically examine the African Solar Drive as part of a proposed process through which the UJ Energy Movement can engage with the broader Southern African community. Not only would this process meet the aims and outcomes for service learning initiatives, it would form the basis for identification of applied research projects that address community needs. The African Solar Drive is reinterpreted in the following section with a view to showing how such a general model of science-society engagement can be implemented. 


\section{RE-INTERPRETING THE AFRICAN SOLAR DRIVE}

The UJ Energy Movement aims to promote the study of alternative energy, energy management and sustainable engineering design. It also aims to deliver engineering graduates who are equipped with the necessary skills and attributes to deal with real-world engineering challenges. Established in 2011, the programme was initially developed as an engineering education research project: a final year design project was defined which entailed developing and racing a solar-powered, electric vehicle across South Africa. However, the initiative has grown into a vehicle for promoting technology innovation, STEM education and multidisciplinary engagement, both internally to students from all faculties at the University and externally to communities, schools and industry partners.

The African Solar Drive was a fledgling instance of science-society engagement. It involved a 10-day road trip from Johannesburg to Kimberley, Upington, Groblershoop, !Kheis, Duineveld, Windhoek, Walvis Bay, and Gaborone. The Drive aimed to engage with as many communities, schools, dignitaries, civil society organisations and institutions of higher education as possible regarding the development of renewable energy technologies, particularly solar energy. At the same time, it sought to raise awareness of STEM education and encourage a 'next generation' of engineers.

The solar-powered car, Ilanga II, is a high-profile means to reach out to communities and its novelty attracts spectators from far and wide. The high-profile nature of the car meant that it could be used to initiate social dialogue on the importance of harnessing energy, and science and technology more generally, for the betterment of quality of life. In this sense, the African Solar Drive is open to being supplemented by a more comprehensive approach to engagement between science and society that is discussed in the final section below.

As part of the African Solar Drive, four formal public seminars were organised: these discussed the car, responsible science and engineering, and the question of sustainability. Outside the formal seminars, nine demonstration events were held where the car was showcased and these, together with the formal seminars, attracted at least 500 participants. Besides the public seminars, the team engaged learner-audiences in games that demonstrated the value and accessibility of science, technology and mathematics. Scholars had to build miniature solar cars with Lego, a tower with nuts, bolts and a skewer, and/or a tower with Jelly Tots. These 'competitions' aimed to encourage scholars to consider a career in science, technology or mathematics by linking creative problem solving to STEM. The demonstration events, often conducted in the street or in public spaces, attracted numerous spectators, and teams were on hand to answer individual questions and to demonstrate the technology used in the car. These 
led to general discussions where scholars and society members could interact with the engineers, scientists, social scientists and administrators of the programme.

The Drive visited organisations from both civil society and academia - the Centre for Clean Energy Research, the Kalahari Conservation Society, SoSolar (a private enterprise), the Botswana Institute for Technology Research and Innovation and YaronsFM. Contact was made with students and academics from Industrial Design, Civil Engineering and Electrical Engineering from the University of Botswana, as well as two other institutions of higher education (Sol Plaatje University and Windhoek Polytech). Botswana's deputy minister of Mines and Energy was also involved in an event in that country. The Solar Drive also visited one secondary school in Botswana and one in Namibia, but made contact with numerous scholars outside school grounds at all the stops. The drive was thus open to a wide cross-section of society.

The Northern Cape and Kalahari, where the drive took place, is one of the most impoverished areas in southern Africa. The choice of this location involved much more than abundant sunshine: these communities would benefit significantly from the development of technologies such as renewable energy. Through networking with the municipal leaders in Groblershoop and other stakeholders, a second engagement, Action Dialogues on Renewable Energy Applications in Rural Areas, is currently rolling out. As such, the African Solar Drive, although limited in impact on its own, assisted in the creation of specific networks that open up the possibility for future innovation (Manzini 2015, 68-74). In the concluding section that follows, we point out the most significant features of the African Solar Drive with a view to elaborating on how these can be enhanced.

\section{EXPANDING THE AFRICAN SOLAR DRIVE}

The African Solar Drive originated so as to achieve the dual aim of promoting technology innovation in the area of renewable energies and encouraging a next generation of Energy Movement members. Of course, it also presented significant benefit to the multi-disciplinary team of student researchers that participated in the Drive. By partnering with schools, universities and municipalities, the Energy Movement grew its return on investment through community engagement, advocacy and marketing exposure. It is nonetheless important to critically reflect on the engagement, and its impact, so as to enable continued growth of the programme.

\section{Reach and targeting: Clarifying the aims of the African Solar Drive}


In future, the Drive needs to plan its activities more systematically so as to ensure that a broad cross-section of stakeholders is included. It should target not only learners, schools and institutions of higher education, but also non-governmental organisations that would benefit from the adoption of sustainable, renewable energy technologies. In this way, the African Solar Drive would become integrated into the broader currents that push these technologies forward. This will create feedback loops within society that ultimately also benefit the African Solar Drive. Malan et al. (2015) point out that multi-stakeholder engagement processes are characterised by social actors appropriating these events for their own interests and pushing forward their own agendas within these events. These often align with the overall objective of the event and thus stakeholders become advocates of the cause. This could contribute immensely to enabling these stakeholders to achieve the overarching objective of technological change, as well as the short term objective of recruiting more learners for STEM education.

Following this engagement, the UJ Energy Movement (housed within the Faculty of Engineering and the Built Environment) has joined forces with the Faculties of Art, Design and Architecture, Management, Economic Sciences, and Humanities on the Izindaba Zokudla project, a multi-stakeholder engagement project, focusing on food systems change, that seeks to strengthen the links between science and society through a focus on food resilience, water and energy in the engineering curriculum. Through such relationships, a comprehensive approach to responsible research and innovation can be developed. To do so, the methodology deployed needs to be flexible enough to deal with engagement activities and with comprehensive investigations where teams of stakeholders collaborate on a given problem. This interdisciplinary collaboration, grounded in community-driven research, has enhanced the focus on sustainable development goals and has led to partnerships with stakeholders met on the African Solar Drive.

The possibility exists to link the African Solar Drive with the Izindaba Zokudla initiative. Food insecurity is particularly acute in poor areas of South Africa, and it is possible that the technologies involved in the solar car could be re-developed to address, say, problems in food gardens through the development of solar-powered water pumps, for instance. It is fascinating to consider how such engagement might inform the design of something as basic as a solar water pump. For example, our anecdotal experience suggests that while the technical detail of such pumps is relatively straightforward, such a pump would need to be easily repairable (within limits), theft proof, portable, and also able to charge mobile phones. The process of developing such secondary requirements for design is, in fact, a key scientific problem (Campbell and Harrison 2015). 


\section{Impact, monitoring and evaluation}

Funders, the university and public officials are particularly concerned with the measurement of impact. This is usually undertaken (including herein) using questionnaire-type surveys, but these, as Chambers (1992) points out, are far removed from the community. It is also necessary to see monitoring and evaluation not as a critically detached activity, but as something that could be undertaken in a participatory way that enhances the project, not for outside funders or observers, but for those who participate therein. It is an opportunity to recruit new participants to the movement, and to improve understanding and practice. Integrating monitoring and evaluation with planning allows participants and stakeholders to take ownership of the activities. This could be achieved by integrating monitoring and evaluation into the media being used, and to allocate formal opportunities for participants and stakeholders to voice concerns. In so doing, we engage in meaningful collaboration with communities so as to democratise research, policy and practice (Vally 2015).

\section{Linkages with civil society and systemic change}

By designing, building and racing high-tech, solar-powered cars, the Energy Movement has developed a platform where students can engage with communities and industry on energy innovation. The Energy Movement, initially designed to function as a project-based educational platform, is used as a public relations and marketing tool to promote STEM education, and as a means of activism for a sustainable future. It connects research to the curriculum by engaging communities, government, NGO's, schools and industry partners.

The catalytic effect of these engagements has propelled the Energy Movement beyond solar energy and, since 2015, it has broadened its focus to include projects relating to global developmental goals. The Energy Movement hosts a series of Innovation Challenges under the banner of \#CoCreateMyCity. These challenges are focussed on smart city solutions relating to energy, transportation, food resilience, water, health and waste management. This includes collaboration on the rural food security and urban farming initiative, Izindaba Zokudla, through which the Energy Movement has linked Engineering students to four groups of farmers and actively engaged them in the development of farming technology. In so doing, these students are exposed to different ways of knowing and seeing, thus illustrating Balwanz and Hlatshwayo's $(2015,148)$ contention that education should not be about individual, private enterprise, but should be seen as 'meaningful social [expression] collaboratively constructed'.

Civil society forms the raw material with which we construct democracy. As Holloway (2010, in Harley 2015) argues: we need to break the systems that have created massive 
inequality, discrimination, and environmental degradation. Building civil society linkages allows others to independently take forward the energy movement. Linking with civil society organisations also situates the energy movement in broader, related currents including food security, water conservation and greater participation in science and technology education.

\section{Implications for higher education}

Society increasingly expects universities to be 'relevant'. This is perhaps most vividly evident in calls to decolonise higher education knowledge in South Africa. This expectation is dismantling the notions of the ivory tower and of the clinical detachment of the scientific method. In its place is the sense that universities must exercise responsibility in overcoming inequality and other socioeconomic and environmental ills. However, for individual researchers, this is a complex task, made more complex by the demands of bureaucracy, teaching, fieldwork and 'playing the publication game'.

Of course, the university as institution needs to be beyond reproach in its own operations by, inter alia, upholding fair labour practices, and avoiding discriminatory behaviour. However, universities in South Africa have been seen to alienate black students and prey on cheap, outsourced labour. This must necessarily be the first step in understanding the role of higher education in effecting social change: institutions of higher education, as social actors, must 'get their own house in order'. The university must act fairly and ethically before it can use its research capacity and networks of impact to encourage others to act fairly and ethically.

Secondly, the university as institution has considerable resources for research, reflection and action. As a centre of such power, it can direct these resources towards encouraging ethical social action on the part of other actors. Some may argue that there is no real power in ethics and morality, and that social power resides in legality and regulation. This may well be the case but, as Iris Young (1994) argues, it does not preclude one from taking a principled ethical position that exposes the politically powerful. The university is perhaps the most powerful repository of critical thought, action and material within society. It is a place where alternatives can be explored with rigour and where decisions can be made in a way that is socially just. Even where agreement is never reached, the university should be a place in which debate is kept open, and focused towards social justice as an end.

Ethical research, therefore, is not about productivity per se, but about leaving social justice in its wake: fairer labour practices, knowledge that is of use to communities, ecological integrity. This moves university research to a place where action is stressed. Of course, action is always embedded in thought and in material procedures that are themselves embedded in prior ethical choices. In this regard, we are seeing the emergence of a new form of action: an action that aims at the betterment of society. This kind of action is relevant to newer forms of 
research - committed research that delivers new form of knowledge, new technologies and new institutions. Such research recognises that knowledge is embedded in technologies, and that technologies construct the values that underpin institutions. This requires an applied science, where knowledge, action and values are realised in a socially just manner, and where socially responsible research and innovation is fostered.

Incorporating the activities of the Energy Movement into the undergraduate curriculum heeds Harley's $(2015,58)$ observation that there is 'an imperative for seriously and urgently considering a radical alternative to post-schooling education'. Such an alternative grapples with the issues facing society in all of their complexity and moves away from a view of education that reinforces power inequality, promotes decontextualized knowledge and skills, and suppresses participation and agency in democratic and social processes (Balwanz and Hlatshwayo 2015). Instead, such post-school education becomes more relevant and responsive to the needs of the community and, in so doing, supports holistic human development (Balwanz and Hlatshawayo 2015).

Of course, this requires that higher education be rewarded for developing professionals that are oriented towards addressing the challenges faced by the urban and rural poor (Vally 2015). At present, such reward is too often derived from meeting the needs of industry, thus negating the impact universities can have as a 'public good' in ameliorating the circumstances of the poor (Vally 2015). As Vally $(2015,162)$ explicates, more academics need to focus on addressing concrete problems in the public domain by moving beyond technical ability and 'linking programmes and projects to community needs and struggles'.

This need, we would argue, is particularly significant in science and engineering education, where students need to be prepared to become what Lotriet (2015) calls 'engagement agents'. It is eminently possible to do this, despite many protestations to the contrary. Nazier and Van Veuren (2015), working with Arts students, show that pedagogic methodologies can be used to conscientise students and enhance the exercise of agency if they are accompanied by a questioning of the role of the lecturer, a critical positioning of content and the continuation of the learning process beyond the classroom. Similar pedagogic methodologies can be deployed in the engineering design classroom if there is a 'shift towards meaningful project-based assessments as an alternative to standardised assessments and teaching to the test' (Vally 2015, 164). It has been the argument of this article that communities and academia (including, specifically, Science and Engineering faculties) should work together to identify community needs, develop participatory design methodologies and undertake to research and develop technologies that meet the needs of those communities.

\section{ACKNOWLEDGEMENTS}


This work is based, in part, on research supported by the National Research Foundation of South Africa (Unique Grant No. 88059) allocated to Naudé Malan.

The authors also wish to acknowledge the participation of Ms Rene Naidoo, Ms Karen Gwamba and Mr Warren Hurter in the execution of the African Solar Drive.

\section{REFERENCES}

Adelman, C. 1993. Kurt Lewin and the origins of action research. Educational Action Research 1(1): 7-24.

Anderson, C. R. and S. M. McLachlan. 2015. Transformative research as knowledge mobilisation: Transmedia, bridges, and layers. Action Research, Prepublished December 9, 2015. DOI: $10.1177 / 1476750315616684$.

Balwanz, D. and M. Hlatshwayo. 2015. Re-imagining post-schooling in Sedibeng: Community-based research and critical dialogue for social change. Education as Change 19(2): 133-150.

Bauer, M. W. 2009. The evolution of public understanding of science - discourse and comparative evidence. Science, Technology and Society 14(2): 221-240.

Borzaga C. and J. Defourney. (Eds.). 2001. The emergence of social enterprise. London: Routledge.

Brydon-Miller, M., D. Greenwood and P. Maguire. 2003. Why action research? Action Research 1(1): 9-28.

Bunders, J. and B. Regeer. 2009. Knowledge co-creation: Interaction between science and society: A transdisciplinary approach to complex social issues. Preliminary Studies and Background Studies, number V.10e. Amsterdam: Athena Institute.

Burns, D. 2012. Participatory systemic inquiry. IDS Bulletin 43(3): 88-100.

Burns, D. 2014. Systemic action research: Changing system dynamics to support sustainable change. Action Research 12(1): 3-18.

Campbell, A. D. and P. Harrison. 2015. A framework for sociotechnical innovation: The case of a human-powered shredder. In The virtuous circle: Design culture and experimentation, ed. L. Collina, L. Galluzzo and A. Meroni, 211-230. Milano, Italy: McGraw-Hill Education.

Chambers, R. 1992. Shortcut and participatory methods for gaining social information for projects. In Putting people first: Sociological variables in rural development, ed. M. M. Cernea, 515-535. $2^{\text {nd }}$ edition. Washington D.C.: World Bank.

Fisher, E. 2007. Ethnographic invention: Probing the capacity of laboratory decisions. Nano Ethics 1: 155-165.

Fowler, A. 2000. NGDOS as a moment in history: Beyond aid to social entrepreneurship or civic innovation? Third World Quarterly 21(4): 637-654.

Freire, P. 2005 [1970]. Pedagogy of the oppressed (30 ${ }^{\text {th }}$ anniversary edition). New York: Continuum.

Harley, A. 2015. Post-schooling people's education. Education as change 19(2): 58-81.

Hart, T. G. B., K. H. Ramoroka, P. T. Jacobs and B. A. Letty. 2015. Revealing the social face of innovation. South African Journal of Science 111(9/10): 1-6.

Holtmann, B. 2015. What it looks like when it is fixed: A case study in developing a systematic model to transform a fragile ecosystem. South Africa: Barbara Holtmann.

Lotriet, H. 2015. Does the engagement between science and society pose risks for intelligent scientific practice? TD: The Journal for Transdisciplinary Research in Southern Africa 11(2): 29-42.

Malan, N. 2015. Design and social innovation for systemic change: Creating social capital for a Farmers' Market. In The virtuous circle: Design culture and experimentation, ed. L. Collina, L. Galluzzo and A. Meroni, 965-978. Milano, Italy: McGraw-Hill Education. 
Malan, N., A. D. Campbell, J. Sibeko, C. van Zyl and R. Benecke. 2015. Service learning for food security: The Izindaba Zokudla experience. https://www.researchgate.net/publication/ 282855236_Service_Learning_for_Food_Security_The_Izindaba_Zokudla_Experience (accessed 31 October 2015).

Manzini, E. 2015. Design, when everybody designs: An introduction to design for social innovation. Cambridge, Massachusetts: The MIT Press.

McIntyre, B. D., H. R. Herren, J. Wakhungu and R. T. Watson. (Eds.) 2009. International Assessment of Agricultural Knowledge, Science and Technology for Development (IAASTD): Synthesis report with Executive Summary: A synthesis of the global and sub-global IAASTD reports. Washington, D.C.: Island Press.

McMichael, P. 2012. Development and social change: A global perspective. $5^{\text {th }}$ edition. Los Angeles: Pine Forge Press.

Miller, S. 2001. Public understanding of science at the crossroads. Public Understanding of Science 10: 115-120.

Moulaert, F. and J. Nussbaumer. 2005. Defining the social economy and its governance at the neighbourhood level: A methodological reflection. Urban Studies 42(11): 2071-2088.

Moulaert, F., D. MacCallum, A. Mehmood and A. Hamdouch. 2013. The international handbook on social innovation. Cheltenham: Edward Arnold.

Murray, R., J. Caulier-Grice and G. Mulgan. 2010. The open book of social innovation. London: Nesta \& The Young Foundation.

Nazier, F. and M. J. van Veuren. 2015. Thinking/making: A discussion of method in the Emerging Arts Activist Programme's Chewing the Cud and Angry Youth Workshops. Education as Change 19(2): 82-111.

Owen, R., J. Bessant and M. Heintz. (Eds.). 2013. Responsible innovation: Managing the responsible emergence of science and innovation in society. Blackwell: Wiley.

Polanyi, K. 2001 [1944]. The great transformation: The political and economic origins of our time. Boston: Beacon Press.

Rahman, A. R. n.d. People's science movements. http://www.anisurrahman.com/files/sw_english/1978 _Peoples_Science_Movements.pdf (accessed 1 April 2013).

Regeer, B., S. Mager and Y. van Oorsouw. 2011. License to grow: Innovating sustainable development by connecting values. Amsterdam: VU University Press.

Rittel, H. W. J. and M. M. Webber. 1973. Dilemmas in a general theory of planning. Policy Sciences 4: 155-169.

Stilgoe, J., R. Owen and P. Macnaghten. 2013. Developing a framework for responsible innovation. Research Policy 42: 1568-1580.

Smithsonian Institution. 2013. Design and social impact: A cross-sectoral agenda for design, education, research and practice. New York: Smithsonian Institution.

Vally, S. 2015. The education crisis and the struggle to achieve quality public education in South Africa. Education as Change 19(2): 151-168.

World Economic Forum. 2014. Towards the circular economy: Accelerating the scale-up across global supply chains. Davos: World Economic Forum.

World Water Assessment Programme. 2012. The United Nations World Water Development Report 4: Managing water under uncertainty and risk. Paris, UNESCO.

Young, I. 1994. Civil society and social change. Theoria: A Journal of Social and Political Theory 83/84: 73-94. 